\title{
DAMPAK PENDIDIKAN KESEHATAN METODE CERAMAH TERHADAP PENCEGAHAN PENYAKIT DEMAM BERDARAH PADA SISWA KELAS 5
}

\author{
Alfianur ${ }^{1}$ \\ 1. Fakultas Ilmu Kesehatan Universitas Borneo Tarakan \\ *E-mail: alfianoer@gmail.com \\ Abstrak
}

Demam Berdarah Dengue (DBD) telah menjadi ancaman di masyarakat Indonesia untuk kurun waktu yang lama. Penyakit ini menunjukan kecenderungan meningkat baik jumlah kasus maupun luas wilayah yang terjangkit. Tujuan Penelitian ini adalah menganalisis Dampak/Pengaruh penyuluhan metode ceramah tanpa media leaflet terhadap perubahan perilaku siswa kelas 5 dalam pencegahan DBD di wilayah puskesmas Juata Permai Tarakan. Metode: Desain penelitian ini adalah quasi experiment: pretest posttest control group design. Besar sampel sebanyak 40 (20 kelompok perlakuan dan 20 kontrol). Pendidikan kesehatan dilaksanakan tiga kali pertemuan di sekolah dalam waktu tiga minggu. Pengumpulan data menggunakan kuesioner pretest dan posttest serta mengunakan uji Wilcoxon Sign Rank Test. Hasil Penelitian menunjukkan ada pengaruh signifikan dalam peningkatan perilaku siswa kelas 5 sebelum dan sesudah pemberian pendidikan kesehatan metode ceramah tanpa media leaflet dengan nilai $\mathrm{p}$ (pengetahuan $=0,000$, keyakinan $=0,000$ sikap $=0,008$ ) namun pada tindakan/psikomotor $=0,130$ tidak ada pengaruh yang signifikan, sedang pada kelompok kontrol didapat nilai $\mathrm{P}$ (pengetahuan $=0,257$, keyakinan $=0,317$ sikap $=0,317$ dan tindakan $=0,180$ ) hasil menunjukan tidak ada pengaruh signifikan dalam peningkatan perilaku siswa kelas 5. Diskusi: Pendidikan kesehatan metode ceramah tanpa media leaflet sangat berdampak/berpengaruh dalam perubahan perilaku responden khususnya pada pengetahuan, keyakinan dan sikap dalam pencegahan DBD.

Kata kunci: Metode Ceramah, Perilaku, Demam Berdarah.

\begin{abstract}
Impact of Health Education by Lecturing Methods On Dengue Fever Prevention To Students Grade 5. Dengue Fever; Demam Berdarah Dengue (DBD) has been a threat in Indonesian society for a long time. This disease shows a tendency to increase both the number of cases and the area affected. The purpose of this study is to analyze the impact / influence of lecturing methods without leaflet media on the change of grade 5 student behavior in the prevention of DBD in the area of puskesmas Juata Permai Tarakan. The design method of this research is quasi experiment: pretest post test control group design. The sample size was 40 (20 treatment groups and 20 controls). Health education held three meetings at school within three weeks. Data collection use pretest and posttest questionnaires and apply Wilcoxon Sign Rank Test. The result of research shows that there is a significant influence in the improvement of the behavior of the 5th grade students before and after the giving of health education of lecturing method without media leaflet with $\mathrm{p}$ value $=0,000$, confidence $=0,000$ attitude $=0,008)$ but on the action $/$ psychomotor $=0,130$ no significant influence, meanwhile in control group got value of $\mathrm{P}$ ( knowledge $=0,257$, confidence $=0,317$ attitude $=0,317$ and action $=0,180$ ) result showed no significant influence in the improvement of student grade 5 behavior. Health education lecturing method without media leaflet very impact / influence in behavior change of respondent especially on knowledge, belief and attitude in prevention of DBD.
\end{abstract}

Keywords: Lecturing Method, Behavior, Dengue Fever 


\section{Pendahuluan}

Demam Berdarah Dengue (DBD) telah menjadi ancaman di masyarakat Indonesia untuk kurun waktu yang lama. Penyakit ini menunjukan kecenderungan meningkat baik jumlah kasus maupun luas wilayah yang terjangkit, secara sporadis selalu terjadi Kejadian Luar Biasa (KLB) setiap tahun. Penyakit ini sering menimbulkan wabah dan menyebabkan kematian bagi banyak orang dalam waktu singkat karena apabila kasus ini terlambat ditangani dapat berakibat buruk bagi penderita.

Angka kejadian DBD kota Tarakan berdasarkan data Dinas Kesehatan Kota Tarakan tahun 2011 ditemukan kasus DBD sebanyak 254 kasus (Insiden rate 132,1 per 100.000 penduduk) dengan jumlah penderita meninggal sebanyak 6 orang, kemudian ditahun 2012 ditemukan peningkatan kasus DBD sebanyak 364 kasus (Insiden Rate 189.3 per 100.000 penduduk) dengan jumlah penderita meninggal sebanyak 7 orang. Menurut Laporan Puskesmas Juata Permai Tarakan mulai Januari hingga September 2013 didapatkan 49 kasus dengan rincian anak umur kurang satu tahun sebanyak 4 kasus, umur 1-4 tahun 12 kasus, umur 5-9 tahun 24 kasus, umur 10-14 tahun 5 kasus, umur 15-19 tahun 3 kasus dan umur 20-44 tahun sebanyak 1 kasus (Dinas Kesehatan Kota Tarakan, 2013).

Penelitian ini menggunakan pendekatan teori yang dikembangkan oleh Lawrence Green tahun 1980 dan ditambahkan konsep Health Belief Model pada bagian belief (kepercayaaan), dimana konsep ini menganalisis perilaku manusia dari derajat kesehatan. Kesehatan seseorang dipengaruhi oleh dua faktor pokok, yakni perilaku (behavior causes) dan faktor di luar perilaku (non behavior causes). Model ini mengkaji masalah perilaku manusia dan faktor-faktor yang mempengaruhinya, serta cara menindaklajutinya dengan berusaha mengubah, memelihara atau meningkatkan perilaku tersebut kearah yang lebih positif.

\section{Metode}

Rancangan penelitian yang akan dilaksanakan menggunakan quasy experimen (eksperimen semu) dengan "pre dan post test control group design" yaitu memberikan suatu perlakuan kelompok dan adanya kelompok Kontrol. Sampel adalah siswa SD kelas 5 yang terpilih sebagai responden saat penelitian dilakukan. Sampel didapat dengan simple random sampling pada siswa kelas 5 di SDN 043 Juata Permai 
Tarakan (20 responden) dan SD Yaditra sebagai kelompok control (20 responden). Kemudian sampel dihomogenkan terlebih dahulu untuk memperkecil bias. Homogenisasi meliputi persamaan karakteristik geografis dan fasilitas pada siswa sekolah. Instrumen yang digunakan dalam penelitian ini adalah kuesioner untuk variabel pengetahuan, keyakinan dan sikap siswa tentang pencegahan penyakit DBD, Sebelum digunakan instrument ini telah dilakukan uji validitas dengan Correlation Pearsons
Test dan uji reabilitas dengan Cronbachs Alfa. Hasil Uji menunjukan Intrument valid dan reliabel.

\section{Hasil}

Pengaruh penyuluhan metode ceramah tanpa media terhadap pengetahuan responden tentang pencegahan DBD

Hasil penelitian menunjukan sebelum perlakuan pengetahuan responden kelompok perlakuan dan kelompok kontrol dapat dilihat pada table 1.

Tabel 1 Distribusi frekuensi rata-rata tingkat pengetahuan kelompok perlakuan SDN 043 Juata Permai dan kelompok control SDS Yaditra Juata Permai Kota Tarakan April 2014

\begin{tabular}{lcccccccc}
\hline \multirow{2}{*}{ Pengetahuan } & \multicolumn{3}{c}{ Kel. Perlakuan } & \multicolumn{3}{c}{ Kel. Kontrol } \\
\cline { 2 - 9 } & \multicolumn{2}{c}{ Pretest } & \multicolumn{2}{c}{ Posttest } & \multicolumn{2}{c}{ Pretest } & \multicolumn{2}{c}{ Posttest } \\
\hline B & \% & N & \% & n & \% & n & \% \\
Cukup & 0 & 0 & 19 & 95,0 & 8 & 40,0 & 10 & 50,0 \\
Kurang & 10 & 50,0 & 1 & 5,0 & 6 & 30,0 & 5 & 25,0 \\
\hline Total & 10 & 50,0 & 0 & 0 & 6 & 30,0 & 5 & 25,0 \\
\hline Uji Normalitas & 20 & 100,0 & 20 & 100,0 & 20 & 100,0 & 20 & 100,0 \\
Shapiro-Wilk & \multicolumn{2}{c}{$\mathrm{p}=0,000$} & \multicolumn{2}{c}{$\mathrm{p}=0,000$} & \multicolumn{2}{c}{$\mathrm{p}=0,001$} & $\mathrm{p}=0,000$
\end{tabular}

Shapiro-Wilk

Uji Wilcoxon $\quad \mathrm{p}=0,000$ (ada beda) $\mathrm{p}=0,257$ (tidak ada beda)

Hasil pengukuran tingkat

pengetahuan pada tabel 1 berdasarkan analisa data pre-post menggunakan uji Wicoxon Sign Rank Test pada kelompok perlakuan dengan nilai $\mathrm{p}=0,000(\mathrm{p}<0,05)$ menunjukan terdapat perbedaan tingkat pengetahuan saat sebelum dan sesudah perlakuan. Hasil analisa data pre-post menggunakan uji Wicoxon Sign Rank Test pada kelompok kontrol dengan nilai $\mathrm{p}=0,257 \quad(\mathrm{p}>0,05) \quad$ menunjukan tidak terdapat perbedaan tingkat pengetahuan saat pretest dengan saat posttest. Hasil penelitian menunjukan pada kelompok perlakuan sebelum dilakukan intervensi didapat sebagian besar memiliki pengetahuan yang cukup dan setelah intervensi pengetahuan responden meningkat menjadi baik. 
Pengaruh penyuluhan metode kerentanan yang dirasakan (perceived ceramah tanpa media leaflet terhadap susceptibility), variabel keseriusan/ keyakinan Responden dalam pencegahan DBD

Hasil penelitian menunjukan keyakinan responden pada variabel keparahan yang dirasakan (perceive severity), variabel manfaat yang dirasakan (perceive benefit), variabel hambatan yang dirasakan (perceive barriers) dapat dilihat pada tabel 2

Tabel 2 Distribusi frekuensi rata-rata keyakinan (belief) kelompok perlakuan SDN 043 Juata Permai, dan kelompok kontrol SDS Yaditra Juata Permai Kota Tarakan April 2014.

\begin{tabular}{|c|c|c|c|c|c|c|c|c|}
\hline \multirow[t]{3}{*}{ Keyakinan } & \multicolumn{4}{|c|}{ Kel. Perlakuan } & \multicolumn{4}{|c|}{ Kel. Kontrol } \\
\hline & \multicolumn{2}{|c|}{ Pretest } & \multicolumn{2}{|c|}{ Posttest } & \multicolumn{2}{|c|}{ Pretest } & \multicolumn{2}{|c|}{ Posttest } \\
\hline & $\mathrm{n}$ & $\%$ & $\mathrm{n}$ & $\%$ & $\mathrm{n}$ & $\%$ & $\mathrm{n}$ & $\%$ \\
\hline \multicolumn{9}{|c|}{ 1. Kerentanan yang dirasakan (perceived susceptibility) } \\
\hline Positif & 7 & 35,0 & 20 & 100,0 & 14 & 70,0 & 13 & 65,0 \\
\hline Negatif & 13 & 65,0 & 0 & 0 & 6 & 30,0 & 7 & 35,0 \\
\hline $\begin{array}{l}\text { Uji Normalitas } \\
\text { Shapiro-Wilk }\end{array}$ & \multicolumn{2}{|c|}{$\mathrm{p}=0,000$} & \multicolumn{2}{|c|}{$\mathrm{p}=0,000$} & \multicolumn{2}{|c|}{$\mathrm{p}=0,000$} & \multicolumn{2}{|c|}{$\mathrm{p}=0,000$} \\
\hline Uji Wilcoxon & \multicolumn{4}{|c|}{$\mathrm{p}=0,001$ (ada beda) } & \multicolumn{4}{|c|}{$\mathrm{p}=0,317$ (tidak ada beda) } \\
\hline \multicolumn{9}{|c|}{ 2. Keseriusan/keparahan yang dirasakan (perceive severity) } \\
\hline Positif & 8 & 40,0 & 20 & 100,0 & 11 & 55,0 & 12 & 60,0 \\
\hline Negatif & 12 & 60,0 & 0 & 0 & 9 & 45,0 & 8 & 40,0 \\
\hline $\begin{array}{l}\text { Uji Normalitas } \\
\text { Shapiro-Wilk }\end{array}$ & \multicolumn{2}{|c|}{$\mathrm{p}=0,000$} & \multicolumn{2}{|c|}{$\mathrm{p}=0,000$} & \multicolumn{2}{|c|}{$\mathrm{p}=0,000$} & \multicolumn{2}{|c|}{$\mathrm{p}=0,000$} \\
\hline Uji Wilcoxon & \multicolumn{4}{|c|}{$\mathrm{p}=0,001$ (ada beda $)$} & \multicolumn{4}{|c|}{$\mathrm{p}=0,655$ (tidak ada beda) } \\
\hline \multicolumn{9}{|c|}{ 3. Manfaat yang dirasakan (perceive benefit) } \\
\hline Positif & 8 & 40,0 & 20 & 100,0 & 13 & 65,0 & 14 & 70,0 \\
\hline Negatif & 12 & 60,0 & 0 & 0 & 7 & 35,0 & 6 & 30,0 \\
\hline $\begin{array}{l}\text { Uji Normalitas } \\
\text { Shapiro-Wilk }\end{array}$ & \multicolumn{2}{|c|}{$\mathrm{p}=0,000$} & \multicolumn{2}{|c|}{$\mathrm{p}=0,000$} & \multicolumn{2}{|c|}{$\mathrm{p}=0,000$} & \multicolumn{2}{|c|}{$\mathrm{p}=0,000$} \\
\hline Uji Wilcoxon & \multicolumn{4}{|c|}{$\mathrm{p}=0,001$ (ada beda $)$} & \multicolumn{4}{|c|}{$\mathrm{p}=0,317$ (tidak ada beda) } \\
\hline \multicolumn{9}{|c|}{ 4. Hambatan yang dirasakan (perceive barriers) } \\
\hline Positif & 8 & 40,0 & 20 & 100,0 & 13 & 65,0 & 15 & 75,0 \\
\hline Negatif & 12 & 60,0 & 0 & 0 & 7 & 35,0 & 5 & 25,0 \\
\hline Total & 20 & 100,0 & 20 & 100,0 & 20 & 100,0 & 20 & 100,0 \\
\hline $\begin{array}{l}\text { Uji Normalitas } \\
\text { Shapiro-Wilk }\end{array}$ & \multicolumn{4}{|c|}{$\mathrm{p}=0,000$} & \multicolumn{2}{|c|}{$\mathrm{p}=0,000$} & \multicolumn{2}{|c|}{$\mathrm{p}=0,000$} \\
\hline Uji Wilcoxon & \multicolumn{4}{|c|}{$\mathrm{p}=0,001$ (ada beda) } & & $157(\mathrm{ti}$ & $\mathrm{ak} \mathrm{ad}$ & beda) \\
\hline
\end{tabular}


Hasil pengukuran perubahan setelah intervensi keyakinan responden keyakinan pada tabel 1.2 Hasil pre-post menggunakan uji Wicoxon Sign Rank Test pada kelompok perlakuan pada semua variabel keyakinan didapat nilai $\mathrm{p}=0,001$ menunjukan terdapat perbedaan keyakinan (belief) sebelum dan sesudah perlakuan. Sedangkan hasil analisa data pre-post menggunakan uji Wicoxon Sign Rank Test kelompok kontrol pada semua variabel didapat nilai $\mathrm{p}>0,05$, hal ini menunjukan tidak terdapat perbedaan keyakinan (belief) saat pretest dengan saat posttest.

Kerentanan yang dirasakan (perceived susceptibility)

Hasil penelitian menunjukan sebelum dilakukan intervensi sebagian besar responden pada kelompok perlakuan sebagian besar memiliki keyakinan mengenai kerentanan yang dirasakan (perceived susceptibility) yang negatif dan setelah intervensi keyakinan responden meningkat menjadi positif.

\section{Keseriusan/keparahan yang dirasakan} (perceive severity)

Hasil penelitian menunjukan pada kelompok perlakuan sebelum dilakukan intervensi didapat sebagian besar memiliki keyakinan mengenai keseriusan/keparahan yang dirasakan (perceive severity) yang negatif dan 
Tabel 3Distribusi frekuensi rata-rata sikap kelompok perlakuan SDN 043 Juata Permai, dan kelompok kontrol SDS Yaditra Juata Permai Kota Tarakan April 2014

\begin{tabular}{|c|c|c|c|c|c|c|c|c|}
\hline \multirow[t]{3}{*}{ Sikap } & \multicolumn{4}{|c|}{ Kel. Perlakuan } & \multicolumn{4}{|c|}{ Kel. Kontrol } \\
\hline & \multicolumn{2}{|c|}{ Pretest } & \multicolumn{2}{|c|}{ Posttest } & \multicolumn{2}{|c|}{ Pretest } & \multicolumn{2}{|r|}{ Posttest } \\
\hline & $\mathrm{n}$ & $\%$ & $\mathrm{n}$ & $\%$ & $\mathrm{n}$ & $\%$ & $\mathrm{n}$ & $\%$ \\
\hline Positif & 7 & 35,0 & 20 & 100,0 & 13 & 65,0 & 14 & 70,0 \\
\hline Negatif & 13 & 65,0 & 0 & 0 & 7 & 35,0 & 6 & 40,0 \\
\hline Total & 20 & 100,0 & 20 & 100,0 & 20 & 100,0 & 20 & 100,0 \\
\hline $\begin{array}{l}\text { Uji Normalitas } \\
\text { Shapiro-Wilk }\end{array}$ & \multicolumn{2}{|c|}{$\mathrm{p}=0,000$} & \multicolumn{2}{|c|}{$\mathrm{p}=0,000$} & & & & \\
\hline Uji Wilcoxon & \multicolumn{4}{|c|}{$\mathrm{p}=0,000$ (ada beda $)$} & \multicolumn{4}{|c|}{$\mathrm{p}=0,317$ (tidak ada beda) } \\
\hline
\end{tabular}

Hasil pengukuran sikap pada tabel 3 berdasarkan analisa data pre-post menggunakan uji Wicoxon Sign Rank Test pada pada kelompok perlakuan dengan nilai $\mathrm{p}=0,000$ menunjukan terdapat perbedaan sikap sebelum dan sesudah perlakuan. Sedangkan hasil analisa data pre-post menggunakan uji Wicoxon Sign Rank Test pada kelompok kontrol dengan nilai $p=0,317 \quad(p>0,05)$ menunjukan tidak terdapat perbedaan sikap saat pretest dengan saat posttest.

Hasil penelitian menunjukan sebelum dilakukan intervensi pada kelompok perlakuan didapat sebagian besar responden memiliki sikap yang negatif dan setelah intervensi sikap responden meningkat menjadi positif.

$\begin{array}{lcr}\text { Pengaruh } & \text { penyuluhan metode } \\ \text { ceramah dengan media } & \text { leaflet } \\ \text { terhadap psikomotor } & \text { dalam } \\ \text { pencegahan DBD } & \end{array}$

Hasil penelitian menunjukan tindakan (psikomotor) responden kelompok perlakuan dan kelompok kontrol dapat dilihat pada tabel 4

Tabel 4 Distribusi frekuensi rata-rata psikomotor kelompok perlakuan SDN 043 Juata Permai, dan kelompok kontrol SDS Yaditra Juata Permai Kota Tarakan April 2014

Psikomotor Kel. Perlakuan Kel. Kontrol

\begin{tabular}{|c|c|c|c|c|c|c|c|c|}
\hline & \multicolumn{2}{|c|}{ Pretest } & \multicolumn{2}{|c|}{ Posttest } & \multicolumn{2}{|c|}{ pretest } & \multicolumn{2}{|c|}{ posttest } \\
\hline & $\mathbf{n}$ & $\%$ & $\mathbf{n}$ & $\%$ & $\mathbf{n}$ & $\%$ & $\mathbf{n}$ & $\%$ \\
\hline Baik & 3 & 15,0 & 6 & 30,0 & 1 & 5,0 & 1 & 5,0 \\
\hline Cukup & 9 & 45,0 & 9 & 45,0 & 8 & 40,0 & 8 & 40,0 \\
\hline Kurang & 8 & 40,0 & 5 & 25,0 & 11 & 55,0 & 11 & 55,0 \\
\hline Total & 20 & 100,0 & 20 & 100,0 & 20 & 100,0 & 20 & 100,0 \\
\hline $\begin{array}{l}\text { Uji Normalitas } \\
\text { Shapiro-Wilk }\end{array}$ & \multicolumn{2}{|c|}{$\mathrm{p}=0,001$} & \multicolumn{2}{|c|}{$\mathrm{p}=0,002$} & & & & \\
\hline Uji Wilcoxon & \multicolumn{4}{|c|}{$\mathrm{p}=0,130$ (tidak ada beda) } & \multicolumn{4}{|c|}{$\mathrm{p}=0,180$ (tidak ada beda) } \\
\hline
\end{tabular}

Hasil pengukuran sikap pada tabel 4 berdasarkan analisa data pre-post menggunakan uji Wicoxon Sign Rank Test pada kelompok perlakuan didapat 
nilai $\mathrm{p}=0,130$, hal ini menunjukan tidak terdapat perbedaan tindakan (psikomotor) sebelum dan sesudah perlakuan. Sedangkan hasil analisa data pre-post menggunakan uji Wicoxon Sign Rank Test pada kelompok kontrol didapat nilai $\mathrm{p}=0,180 \quad(\mathrm{p}>0,05)$ yang menunjukan tidak terdapat perbedaan tindakan (psikomotor) saat pretest dengan saat posttest. Hasil penelitian menunjukan sebelum dilakukan intervensi sebagian besar responden pada kelompok perlakuan sebelum dilakukan intervensi didapat sebagian besar memiliki psikomotor yang cukup dan kurang dan setelah intervensi sebagian besar masih cukup dan kurang.

\section{Pembahasan}

\section{Pengaruh penyuluhan metode ceramah tanpa media terhadap pengetahuan responden tentang pencegahan DBD}

Hasil uji Wilcoxon Sign Rank Test menunjukan bahwa ada peningkatan pengetahuan responden pada kelompok perlakuan setelah dilakukan intervensi sedangkan pada kelompok kontrol tidak terjadi peningkatan pengetahuan. Hasil ini menunjukan ada pengaruh yang signifikan metode ceramah tanpa media leaflet dalam peningkatan pengetahuan siswa SD kelas 5 dalam pencegahan Demam Berdarah.

Meningkatnya pengetahuan responden pada kelompok yang diberikan pendidikan kesehatan dengan metode ceramah tanpa media sesuai pendapat Azwar dalam Maulana (2013) bahwa pendidikan kesehatan adalah kegiatan yang dilakukan dengan menyebarkan pesan, menanamkan keyakinan sehingga masyarakat tidak hanya sadar, tahu dan mengerti tetapi juga mau dan dapat melakukan anjuran yang berhubungan dengan kesehatan.

Pengaruh penyuluhan metode ceramah dengan media leaflet terhadap keyakinan Responden dalam pencegahan DBD

Hasil uji Wilcoxon Sign Rank Test menunjukan bahwa ada perubahan keyakinan (belief) pada kelompok perlakuan dibandingkan dengan kelompok kontrol. Hal ini menunjukkan ada pengaruh yang signifikan metode ceramah tanpa media leaflet dengan peningkatan keyakinan (belief) responden. Hasil penelitian ini juga sesuai dengan teori Health Belief Model (HBM) di dalam Edberg (2010) bahwa seseorang yang telah mendapatkan informasi dan keterampilan terkait dengan suatu penyakit akan mempunyai 
persepsi yang baik pula terhadap penyakit tersebut.

\section{Pengaruh penyuluhan metode ceramah dengan media leaflet terhadap sikap responden dalam pencegahan DBD}

Hasil uji Wilcoxon Sign Rank Test menunjukkan bahwa ada perubahan sikap responden pada kelompok perlakuan namun tidak ada perubahan sikap responden pada kelompok kontrol. Hasil ini membuktikan bahwa ada pengaruh yang signifikan metode ceramah tanpa media leaflet dengan perubahan sikap responden dalam pencegahan Demam Berdarah. Hasil ini didukung oleh penelitian yang dilakukan oleh Nguyen (2003) bahwa pendidikan kesehatan sangat berpengaruh kuat dalam peningkatan pengetahuan, sikap dan tindakan ibu terhadap pencegahan DBD.

Sikap sosial terbentuk dari adanya interaksi sosial yang dialami individu. dalam interaksi sosial terjadi hubungan sebagai individu maupun anggota kelompok sosial yang saling mempengaruhi. Interaksi sosial ini meliputi hubungan antara individu dengan lingkungannya baik lingkungan fisik maupun lingkungan biologis yang ada di sekelilingnya. Faktor yang mempengaruhi pembentukan sikap

adalah pengalaman pribadi, kebudayaan, orang yang berpengaruh, media massa, institusi pendidikan maupun lembaga agama. Dengan perkataan lain, sikap merupakan perubahan yang meniru perilaku orang lain karena orang lain tersebut dianggap sesuai dengan dirinya (Azwar, 2005).

Pengaruh penyuluhan metode ceramah dengan media leaflet terhadap psikomotor dalam pencegahan DBD

Hasil uji Wilcoxon Sign Rank Test menunjukan bahwa pada kelompok perlakuan dan kelompok kontrol tidak terjadi perubahan tindakan (psikomotor) yang signifikan. Hasil ini menunjukkan bahwa penyuluhan metode ceramah tanpa media dan kelompok kontrol tidak ada pengaruh dalam perubahan tindakan (psikomotor). Hal ini sesuai dengan teori pendidikan dan perilaku kesehatan, dalam Notoatmodjo $S$ menyebutkan bahwa pendidikan kesehatan merupakan 'behavioral invesment' jangka panjang. Hasil invesment pendidikan kesehatan baru dapat dilihat beberapa tahun kemudian, sedangkan dalam waktu yang pendek (immediate impact) pendidikan kesehatan hanya menghasilkan perubahan atau peningkatan pengetahuan saja. 
Faktor frekuensi pemberian pendidikan kesehatan juga sangat mempengaruhi peningkatan pengetahuan responden, dalam penelitian ini pada kelompok perlakuan diberikan pendidikan kesehatan sebanyak tiga kali sehingga metode ceramah tanpa media pun cukup efektif jika dilakukan berulang-ulang dalam peningkatan pengetahuan siswa kelas 5 tentang pencegahan demam berdarah, hal ini sesuai dengan pendapat Sunyoto (2006) bahwa sesuatu yang diulang-ulang cenderung tertanam dalam jiwa manusia.

\section{Kesimpulan}

Terdapat dampak/pengaruh yang signifikan penyuluhan metode ceramah dengan media leaflet terhadap perubahan perilaku siswa kelas 5 dalam pencegahan DBD jika dibandingkan dengan kelompok yang tanpa diberikan perlakuan (kontrol) terutama pada pengetahuan, Keyakinan dan sikap.

\section{Saran}

Penyuluhan dengan metode ceramah hendaklah disertai dengan pemberian media atau alat penyuluhan sehingga efektif dalam meningkatkan perilaku siswa dalam mencegah DBD, Penelitian lanjutan dapat dilakukan dengan cakupan yang lebih luas, meneliti metode dan media penyuluhan yang seperti Booklet, Komik, film dan sebagainya sehingga ditemukan metode dan media yang paling efektif bagi perubahan perilaku siswa dalam pencegahan DBD yang pada akhirnya dapat menurunkan angka kejadian DBD terutama pada anak.

\section{Referensi}

Ahmed N. (2007). Knowledge, attitude, and practice of dengue fever prevention among the people in male malvides. Chulalongkorn University.

Arikunto, S. (2006). Prosedur Penelitian Suatu Pendekatan Praktik (edisi revisi 6). Rineka Cipta: Jakarta

Azis. A.H. (2005). Pengantar Ilmu Keperawatan Anak. Salemba Medika: Jakarta

Azwar. S (2011). Sikap manusia: Teori dan Pengukurannya. Edisi 2. Yogyakarta: Pustaka Pelajar

Burke, D.S., Nisalak, A., Johnson, D. E. \& Scott, R.M. (1988). A prospective study of dengue infections in bangkok. Am J Trop Med Hyg. 38(1), 172-180

De Porter. B. (2000). Quantum leaching. Terjemahan. Bandung: KaifaMizan. 
Dinas Kesehatan Kota Tarakan. (2012).

Profil Kesehatan Dinas Kesehatan

Kota Tarakan tahun 2012. Tarakan

Federer WY. (1963). Experimental

Design: Theory and Application.

New York: Mac Milan.

Green LW,. Kreuter M.W. (2000).

Health Promotional Planning: An

Educational and Enviromental

Approach. Second Edition.

Toronto: Mayfield Publishing

Company.

Gubler DJ. (1998). Dengue and dengue hemorrhagic fever. Clin Microbiol Rev. Vol 11: 480

Guerdan.B.R. (2010). Dengue fever/dengue hemorrhagic fever. Amarican Journal of Clinical Medicine. Volume seven. Hal: 5153

Kementerian Kesehatan RI. (2012).

Profil Kesehatan Indonesia 2012. Jakarta.

Khun S,. Manderson L. (2007). Community and school-based health education for dengue control in rural cambodia: a process evaluation. PLoS Neglected Tropical Diseases Vol 1. Hal 143.

Kroeger, A., Nathan, M., Hombach, J.; World health organization TDR reference group on dengue. (2004).
Dengue. Nat Rev Microbiol, 2 (5), 360-361

Maulana, H.D.J. (2013). Promosi Kesehatan. Jakarta: EGC

Nasronudin. (2011). Penyakit Infeksi Di Indonesia Solusi Kini Dan Mendatang. Edisi Kedua. Surabaya: Pusat Penerbitan dan Percetakan Unair

Notoadmodjo, S. (2007). Kesehatan Masyarakat: Ilmu dan Seni. Jakarta: Rineka Cipta

Notoadmodjo, S. (2010a). Ilmu Perilaku Kesehatan. Jakarta: Rineka Cipta

Notoadmodjo, S. (2010b). Promosi Kesehatan: Teori dan Aplikasi. Jakarta: Rineka Cipta

Nursalam. (2013). Metodologi Penelitian Ilmu Keperawatan: Pendekatan Praktis. Edisi 3. Jakarta: Salemba Medika.

Santrock. (2007). Child Development $11^{\text {th }}$ ed. New York: The Mc Graw Hill Companies.

Sanyoto (2006). Metode Perancangan Komunikasi Visual Periklanan. Yogyakarta: Dimensi Press.

Soedarto. (2012). Demam Berdarah Dengue. Jakarta: Sagung Seto.

Soegeng S. (2004). Demam Berdarah Dangue. Tinjauan dan Temuan Baru di Era 2003. Surabaya: Airlangga University Press. 
Alfianur, Dampak Pendidikan Kesehatan Metode Ceramah Terhadap Pencegahan Penyakit Demam Berdarah Pada Siswa Kelas 5

Sunaryo. (2004). Psikologi Untuk World Health Organization (WHO).

Keperawatan. Jakarta: EGC

(1997). Dengue and Dengue

Wong. D.L. (2005). Nursing Care of Haemorrhagic Fever: diagnosis, Infant and Children. St. Louis: Treatment, Prevention and mosby

Control. $2^{\text {nd }}$ edition. Geneva:

World Health Organization (WHO).

WHO.

(2002). Dengue Haemorrhagic

Fever. Fact sheet N.117. Geneva:

WHO. 